\title{
Spatial accessibility as a driver to build an inclusive and proactive city
}

\begin{abstract}
Providing the largest number of persons the possibility to actively move and contribute to their own well-being also depends on the spatial accessibility to urban environment. From this perspective, the present article addresses two main questions: to what extent can the physical arrangement of public spaces play a key role in enabling individuals' capabilities to lead a healthy life, and how can accessibility affect urban regeneration. Accessibility is here understood as a fundamental right of citizenship and as a prompt to set the reflection on sensorial/cognitive/motor disabilities within a broader frame, covering many fields of urban agendas: social justice and health, sustainable mobility and Universal Design, and nature-based solutions. COVID-19 distancing measures have further emphasized the importance of these issues, stressing the need to make urban spaces walkable and usable for the most vulnerable citizens. The research Proactive City, developed at the University of Trieste (IT), offers input into this debate. The outcomes of design workshops in the Italian region Friuli Venezia Giulia, as well as of collaboration activities with the Regional Administration, provide technical and methodological recommendations to rethink "accessibility for all”, not as synonymous with special solutions addressed to persons with disabilities but as an overall approach to envisaging any urban transformation and policy.
\end{abstract}

Keywords: inclusion, accessibility for all, Proactive City, urban regeneration, COVID-19 pandemic

\section{Introduction: accessibility for all as a strategic urban issue}

Moving across urban spaces in an autonomous and sustainable way (on foot, by bicycle, by public transport) is becoming an increasingly difficult task for everyone, especially for the most fragile citizens (the elderly, children, persons with disabilities). Many physical obstacles preclude an extensive use of streets and squares, parks and gardens, schools, social and health care services, and cultural equipment. The material configuration of public spaces is less and less "democratic" and open to welcoming different social practices, bodies, and capabilities (Francis, 1987), thus contributing to severe social and spatial inequalities. Although accessibility is currently recognized as a request of building and planning regulations across Europe, their focus is often on the removal of single barriers to mobility of disabled persons. Instead of fostering real inclusion, this sectoral approach tends to justify a "functionally accessible social and spatial discrimination” (Accolla, 2009). The risk of solutions solely designed to meet a defined user group's needs is to recreate discriminatory situations for the individuals they aim to include. According to Universal Design (UD) philosophy, urban environment should be "usable by all people, to the greatest extent possible, without the need for adaptation or specialized design” (United Nations, 2006, art. 2), whereas the physical configuration of cities should accommodate individuals with diverse motor, cognitive, and sensory capabilities. In the light of these considerations, accessibility for all is here understood as the material arrangement of infrastructures, public spaces, and facilities, allowing their use by the largest number of persons through soft mobility: by walking as well as using a wheelchair or carrying a baby stroller. The focus is on the spatial connection and comfort of the routes that 
a person covers daily (from their home to collective places and welfare equipment), and on the overall quality of urban environment that can support social interaction. The assumption is that taking accessibility as an urban and social capital can address deep rethinking of cities as more inclusive contexts (Brain, 2019), according to the aim to "leave no one behind" (Cities for All, 2019). Specifically, the present article discusses how urban spaces can prevent or enable access, participation, and social inclusion, depending on how they are planned and built.

Since 2020, the effects of the measures against COVID-19 pandemic have further highlighted the impact of reduced autonomous mobility on the well-being of large parts of the urban population. Although with differences in national contexts, social/physical distancing and limitation in the use of public spaces and services are producing serious effects on the psychophysical health of those already suffering from major vulnerabilities (due to age, loneliness, and illnesses, lack of economic and social resources, poor housing conditions, etc.). The situation is often worsened by the prior inadequacy of the spatial configuration and accessibility of the places where education, social facilities, and health care are provided. However, the need for soft mobility connecting public spaces and essential services has been brought to the fore well before the pandemic, both in Europe and elsewhere, by the growing variety of lifestyles, worsening of social and economic disparities, and increase in the age of urban dwellers. These requests and trends have combined with the just claims by people with disabilities, leading to the assumption of UD principles by international policies (World Health Organization, 2001; European Commission, 2010; United Nations, 2016; Bencini et al., 2018). In parallel, the topic of walkability has gained momentum within a broader reflection on urban well-being and equity (Speck, 2018; Blečić et al., 2020), and a number of international city networks and design experiences have focused on the issues of healthy, active, and inclusive cities (Nike, 2015; Shah et al., 2015; Tsouros, 2015), showing the capacity of mobility to combine with environmental sustainability, health, and inclusion within innovative approaches to city planning and design. Presently, accessibility for all can be understood as a strategic issue of urban agendas and as a viewpoint from which many fields covered by the recent addresses and funding for a green transition (the European Green Deal, the post-COVID Recovery and Resilience Plans of Next generation EU, and the New European Bauhaus) can be co-ordinately tackled: social justice, physical and digital access to health and care services, people-centred spatial planning and design, sustainable and nature-based solutions (European Commission, 2020, 2021). The perspective urban policies are prompted to take on is that of a "preventive urbanism" (Dorato, 2020), in which the issues of taking care in advance of both environmental and people's health are joined with a deep rethinking of welfare services, their spatial layout, and urban setting (Marchigiani, 2022). In this frame, by integrating pedestrian and bicycle mobility, public transport, the provision of green areas and facilities, making city spaces accessible contributes to health and well-being precisely because it allows to deal with many challenges: from limiting the impacts of urbanization processes and vehicular traffic on environment and climate, to encouraging physical activity to help reduce the onset of chronic illnesses due to sedentary lifestyles and ageing. In terms of economic sustainability, the relations among preventive actions to improve the quality and use of welfare services, the rationalization of public spending on social and health care, the reduction of costs borne by individuals and families when resorting to market-provided facilities are evident.

In fact, the attention given these issues is strong and recurring. However, the coordination of the variety of skills and tools dealing with accessibility, as well as their assumption as constitutive elements of urban policies and design, are still far from being taken for granted in the upgrading of city spaces. It is precisely with the aim to develop instruments and strategies helping overcome the gap between innovative approaches and current public administrations' 
and professionals' routines that the group Trieste Inclusion \& Accessibility Lab (TRIAL) has been working at the University of Trieste since 2019, in the frame of the research Proactive City: The city as a gym for active design. The hypothesis is that the physical configuration of places can play an enabling role in supporting social interaction, stimulating healthy and dynamic behaviours, and reactivating a person's "capabilities" to autonomously contribute to their own well-being, according to their different needs, functionalities, and potentials (Sen, 1987). Moreover, taking on a "proactive perspective" can help transform technical and cultural approaches to urban regeneration towards more comprehensive and people-centred solutions. The article investigates how this perspective can work in practice, when integrating urban design and planning. The second chapter provides an overview of the "action and by design" methodology and objectives of the research Proactive City. The third chapter draws practical inputs from the results of pilot experiences developed in the Italian region Friuli Venezia Giulia, namely design workshops and activities in collaboration with the Regional Administration addressed to build spatial solutions, planning guidelines, and Information and Communication Technology (ICT) tools supporting accessibility-oriented urban interventions and policymaking. In the fourth chapter, the article further discusses the technical and cultural dimensions of accessibility as the outcome of a proactive approach to the renewal of public spaces and equipment, organization of participatory design processes, and integration of a variety of strategies, scales, fields, and instruments of urban regeneration. Finally, from a postCOVID perspective, the conclusions reflect on the relevance of the issues of inclusive, soft, and healthy mobility in fostering - in collaboration with universities - a deep rethinking of urban planning and design.

\section{Proactive City: objective and methodology}

In the frame of urban transformations and policies, accessibility for all to collective spatial assets can be translated into many operational fields: the material refurbishment of public spaces as usable by people with different abilities; the combined implementation of mobility, green and healthy infrastructures, and equipment for outdoor activities; the arrangement of the spatial location and organization of social, educational, and health care facilities. To investigate these issues, the research Proactive City focuses on the enabling potential of urban space. Going beyond the simple removal or mitigation of the impacts of physical barriers in urban contexts, the research understands cities as gyms for active design. The main objective is to rethink urban contexts as places where the configuration of public spaces, the location of services, and green and sports areas are part of strategies aimed at reactivating people's capabilities to move independently (mainly by walking) while preventing the worsening of spatial, social, and health imbalances.

Relevant to the present discussion, the concept of "motility" has been used by Vincent Kaufmann (2011: 37-46) to describe the many forms of interaction between urban spaces and social practices. Talking about motility means reflecting on the active role urban populations can perform in the city in relation to the material configuration of their living and working contexts. Motility is referred to as a conditioned, conditioning, and enabling capital, taking force when a person's specific physical capabilities match with adequate levels of accessibility to urban assets. In turn, the degree of expression of motility affects the development of additional capabilities, aimed at adjusting one's lifestyle to contextual conditions. Moreover, going beyond mere adaptation, the presence of spaces that stimulate these abilities can eventually lead to new social practices; this is an important aspect when rethinking urban welfare through citizens' involvement (Marchigiani, 2020). In other words, if the link between 
healthy places and healthy people is understood as inseparable (Commission on Social Determinants of Health, 2008), disability has to be interpreted not so much as the condition of single individuals, but as the outcome of the daily interaction with a living environment that is more or less able to enhance their motor, sensory, and cognitive potentials. In a stable or permanent way, these potentials change for everyone, in the different phases of their existence. A fundamental factor in making cities proactive is, therefore, joining actions on places and people: on the physical configuration of urban space; on the ways public services are delivered; and on the active role and involvement of citizens, meant not only as city users but also as providers of knowledge and experience when conceiving physical transformations and services reorganization.

The research Proactive City addresses these topics by taking on an interdisciplinary approach and by linking different expertise: from planning and inclusive spatial design to healthcare and rehabilitative therapy. In addition, Proactive City is an "action and by design" research, oriented towards a strong interaction between theory and practice, according to a "reflective practitioner's" attitude (Schön, 1984). Its methodology is based on empirical activities, with the aim to develop two intertwined paths: the exemplification of spatial solutions through design experiences involving citizens, local stakeholders, and administrations; the definition of tools and approaches to innovate public policies.

\section{Results from pilot cases}

Below, the aims and results of three different and complementary case studies are presented. The first one focuses on the importance of the citizens' participation in the renewal of urban spaces through public discussion, multicriteria analysis, and digital tools as devices in support of people's engagement. The second one shows how the issues of accessibility foster innovation in the ways soft mobility in between facilities is planned and designed. Finally, the third case refers to the development of guidelines and policies meant to help public administrations accept accessibility as a fundamental component of urban planning and spatial upgrading. The outcomes of these experiences support the proposal of a methodological path towards the transformation of urban environments into proactive cities.

\subsection{Sant'Antonio Square (Trieste): public discussion}

The first case study was offered by the upgrading of Sant'Antonio Square, promoted by the Municipality of Trieste as one of the latest steps of a long-standing regeneration process of the city historical centre, begun in the 1990s. A participatory design experience was developed in spring 2019 by experts from TRIAL in collaboration with members of Progettiamo Trieste (a local association of young activists). The general aim was to raise wider public awareness of the importance of providing public spaces that are accessible for all. This scope was addressed through the definition and testing of tools used to listen to vulnerable groups' requests from the initial phase of the design process onwards. During a one-week workshop, students from the University of Trieste had the opportunity to debate with the Administration technical staff, the architect in charge of the preliminary plan of the square (Maurizio Bradaschia), and different stakeholders (Regional Board of Disabled People's associations, Italian Blind Persons' Union, and Pro Senectute association). The main objective was to assess - in a shared way by students and expert designers, the elderly and persons with motor and visual disabilities - which of the four proposals defined by the architect (Comune di Trieste, 2019) could best meet a number of identified fundamental requirements. 
The participatory process was supported by the use of decision-making tools to help match and evaluate different solutions, and improve the quality of the final project. Specifically, the listening process was started from on-site mapping and filling in of qualitative questionnaires that had already been tested by TRIAL and the Municipality in the prior project Accessibility Laboratory - Labac (2011-2016), promoted by the Province of Trieste to map urban itineraries according to their degree of accessibility by the most fragile city users (Garofolo et al., 2018). First, practicability, safety, environmental quality, usability, and reachability were identified as the main requirements for the square. Then, in order to choose among the project proposals, a general grid was defined, linking the types of stakeholders to more detailed design criteria (Table 1).

Table 1: Trieste. The multi-criteria assessment grid.

\begin{tabular}{|c|c|c|}
\hline Stakeholders & Requirements & Criteria \\
\hline & \multirow{5}{*}{ Practicability } & Readability of spatial elements \\
\hline & & Path continuity \\
\hline & & Path width \\
\hline & & Path inclination \\
\hline & & Sound aspects \\
\hline \multirow{3}{*}{$\begin{array}{l}\text { Physically } \\
\text { disabled }\end{array}$} & \multirow{5}{*}{ Safety } & Discontinuity detectability \\
\hline & & Readability of obstacles \\
\hline & & Horizontal surface uniformity \\
\hline \multirow{2}{*}{ Visually impaired } & & Materials invariability \\
\hline & & Sound aspects \\
\hline \multirow{9}{*}{ The elderly } & \multirow{4}{*}{$\begin{array}{l}\text { Environmental } \\
\text { quality }\end{array}$} & Perception \\
\hline & & Well-being \\
\hline & & Microclimate \\
\hline & & Illumination \\
\hline & \multirow{3}{*}{ Usability } & Ergonomics \\
\hline & & Material properties \\
\hline & & Reflexivity \\
\hline & \multirow[b]{2}{*}{ Reachability } & Public transport proximity \\
\hline & & Availability of dedicated car parks \\
\hline
\end{tabular}

Source: Chiarelli (2020).

By adopting a multi-criteria assessment model, each participant was asked which requirement weighed more, with the aim to recognize the design alternative that could offer the highest level of accessibility in relation to the preferences of the majority of stakeholders. This approach helped understand how the importance given to accessibility issues varies according to the stakeholders' needs and capabilities. For example, for the elderly, the most important requirement was safety; for the visually impaired, practicability, usability, and safety were equally fundamental; for physically disabled persons, not only the practicability of the space but also its reachability were defined as priorities. Finally, a computer software was used to analyse the answers by equally considering the different points of view. The outcome was the choice of one proposal (number 4), that however revealed certain critical issues (Figure 1). The workshop therefore developed a second listening phase in order to allow the participants to suggest measures to overcome the identified problems and review the project during its further steps. In addition, the Administration also considered feedback from citizens by delivering a public on-line questionnaire. The overall set of collected suggestions prompted the Municipality technical staff to ask the architect for a new version of the project, considering the 
needs expressed by the citizens during the entire process. The Administration is currently working on that version of the proposal in order to develop the final design phase.

This experience clearly demonstrates that participation counts. Knowing the needs of citizens allows designers to calibrate their choices and come up with solutions that are better tailored to people's requests. The challenge is to not only consider the design and quantitative criteria on accessibility that are formally dictated by the law (in Italy, major references are the Ministry Decrees no. 239/1989 and no. 503/1996), and that predominantly focus both on the removal of single obstacles to motor/sensory disabilities and on the definition of minimum dimensions of open areas and buildings. The aim is also to give voice to the performance requests that are expressed by the actual users of public space. The assumption is that, in order to be more effective, spatial strategies and solutions should be ordinarily built through processes of designing with people, open to the contribution of the common knowledge of persons with different vulnerabilities, capabilities and needs, whose daily struggles are also the result of disabling environments.

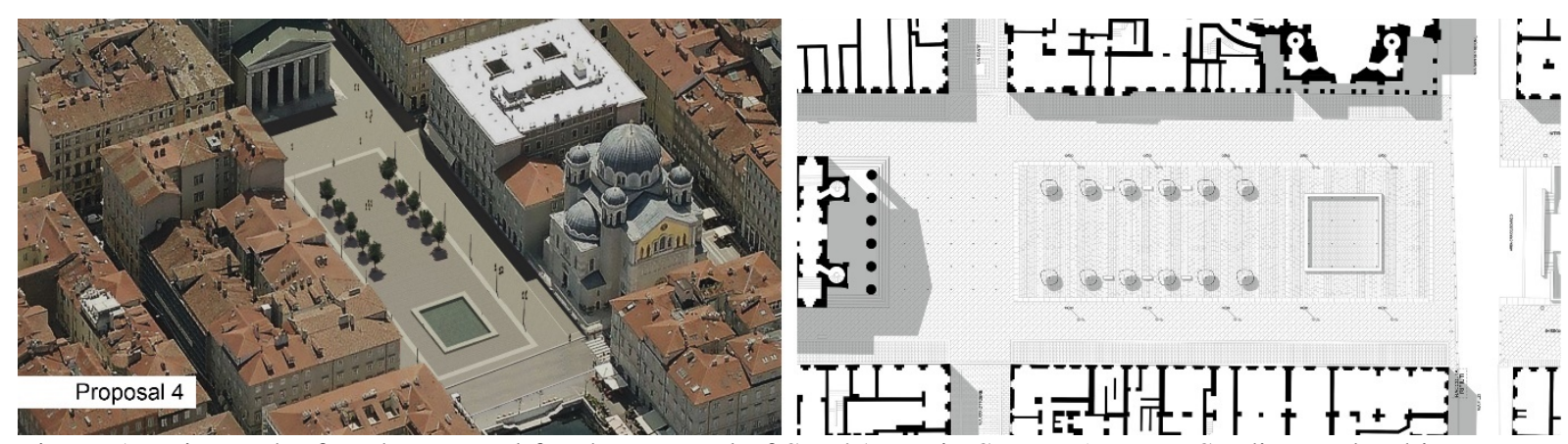

Figure 1: Trieste: the fourth proposal for the renewal of Sant'Antonio Square (source: Studio Bradaschia, Municipality of Trieste, 2019).

\subsection{Grado: healthy and green routes}

Grado was the location of a second design workshop, held in summer 2019. The choice of the place was motivated by the complexity and dynamism of this small city in Friuli Venezia Giulia, and by the interest to further question the interactions between planning and design issues dealing with accessibility. Grado is an important tourist destination in the region, with an intense seasonal change of habits and population (8,000 inhabitants in winter, 80,000 in summer). The local administration is implementing innovative projects for public spaces, with specific attention given to green networks, walkability, and cycling. The two most relevant planning initiatives concern the Plan for the Removal of Architectural Barriers within public buildings and open spaces (PEBA; established by the Italian Laws no. 41/1986 and 104/1992), and the Sustainable Urban Mobility Plan (PUMS; Decree of the Italian Ministry of Infrastructures and Transports, 04 Aug. 2017; see also Rupprecht Consult, 2019). However, further work is needed towards their integration into overall urban strategies. Again, the workshop approach was based on the direct practice of the city. For two weeks professors and students walked across urban spaces, met technicians from the Municipality and the Region, and took part in surveys with disabled people's associations. The organization of training seminars on accessible cities, given by experts engaged in national planning and design experiences, aimed to provide inputs both to the Administration and to professionals and citizens. Meanwhile, design work focused on proposals for healthy and green routes, namely itineraries connecting residential urban districts to the green and pedestrian areas at the back of the beach. The challenge was to imagine Grado as a small capital of active life, where everyone can move safely all year long; as a city where collective spaces and equipment work in an 
integrated manner, offering the largest number of people the opportunity to perform outdoor activities; and as a place where tourism can become a lever both to develop economies and to upgrade the quality of everyday life.

The selection of the streets and paths to refurbish was oriented by considerations made on a larger, urban scale. Design work took the public facilities already available in the residential neighbourhood - schools, parks, sports areas, and healthcare facilities for the elderly - as keystones of the new urban route and of the entire soft mobility system. On a more detailed scale, the proposals focused on opening up the fences of public buildings and plots, and on redrawing their intermediate spaces with the streets, in order to multiply their services and offer them to a larger variety of users (Figure 2a). The solutions consisted of the design of adaptable collective spaces, where casual encounters and interactions can take place, and where inclusive playgrounds and equipment for outdoor activities are not conceived as intrusive furniture but as an integral part of multitasking, continually changing, and interlinked urban spaces, inviting to freely act in the city. In all projects, green materials and nature-based solutions for making urban soil permeable and resilient to climate change were among the main elements, showing how accessibility, health, and environmental issues can be jointly addressed in ordinary interventions on public spaces. Wherever possible, the students' proposals converged on the increase of pedestrian areas and of lanes specifically dedicated to bicycles (separation of walking and cycling was recognized as necessary and welcome by all the users), combined with the reorganization of parking facilities and public transport services. In line with the EU Road Safety Policy Framework 2021-2030 (Adminaité-Fodor \& Jost, 2020), when the co-presence of different mobility modes in the same space could not be avoided, the solution was to design $30 \mathrm{~km} / \mathrm{h}$ streets as public spaces meant to protect the most vulnerable road users by hosting cars in reduced vehicular areas, adding chicanes and trees to articulate the street section, and lowering car speed limits (Figure 2b). A common component of all the interventions was the creation of a continuous system of pedestrian crossing platforms and pavements, where the choice of surface materials and the location of street furniture would help orientation and avoid obstacles not only to persons with motor and sensory disabilities but to everyone else (Marchigiani, 2022).

The workshop strengthened the awareness that inclusive design is not synonymous with special solutions and devices. The challenge is to imagine spaces that are without barriers and walkable by everyone, trying to negotiate in advance the conflicts among different persons and ways/capabilities to move (pedestrians vs. cyclists, motor vs. visual or cognitive abilities). Indeed, one of the outcomes was the awareness that the main obstacles to a proactive city are not to be found in the lack of detailed technical solutions (in fact, to a large extent already developed by urban planning, regulations, and design), but in the difficulty in combining them as regular and interconnected components of a different (and multiscale) way of transforming urban contexts into people-centred and environmentally sustainable habitats. 

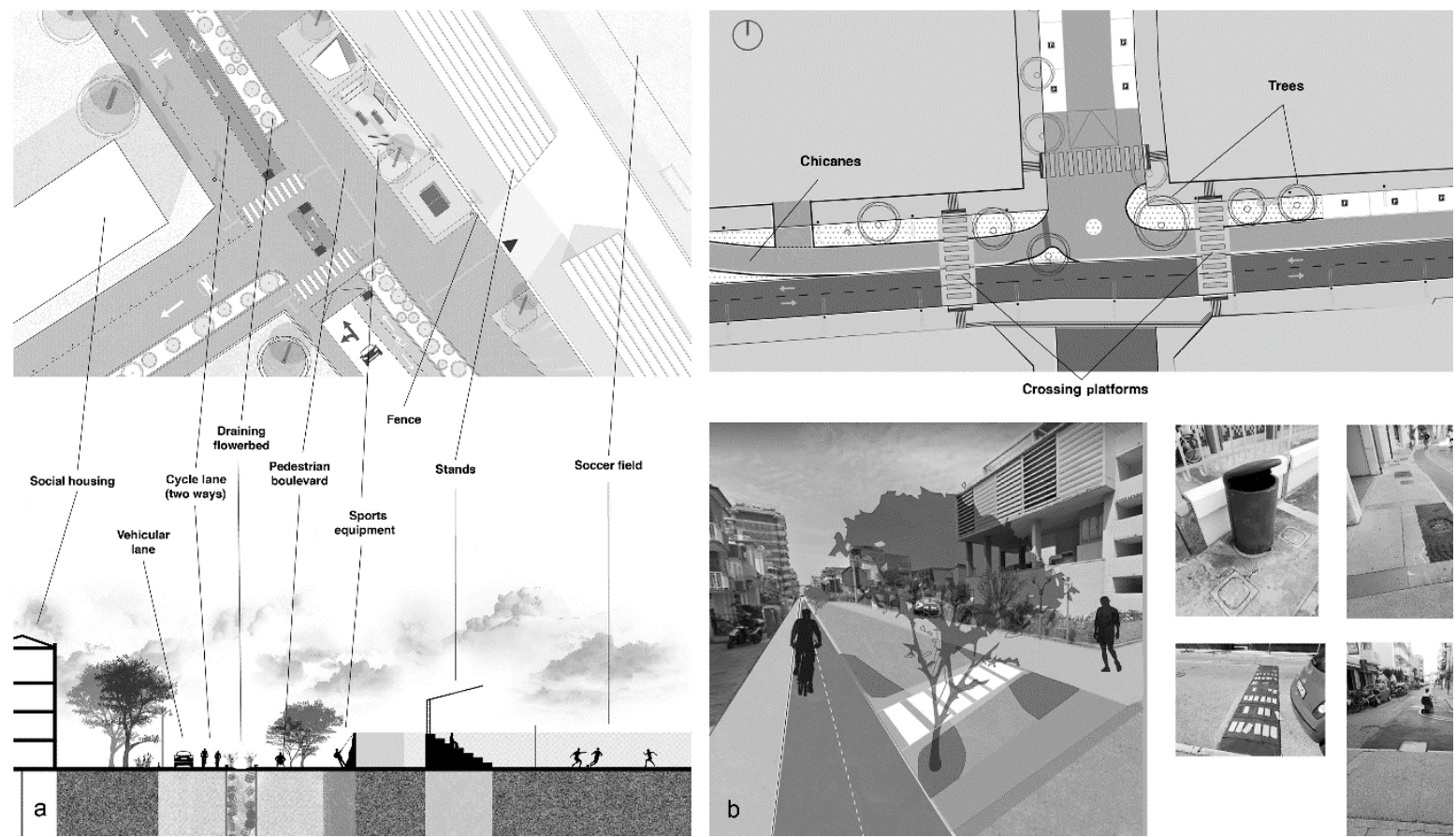

Figure 2. Grado: a) the redesign of spaces in between sports equipment and the streets; b) $30 \mathrm{~km} / \mathrm{h}$ streets (source: research documentation of Proactive City, University of Trieste, 2019).

\subsection{Region Friuli Venezia Giulia: change in urban policymaking}

Further operational fields for conceiving a proactive city have opened up thanks to an agreement signed in 2020 by the Universities of Trieste and Udine with the Region Friuli Venezia Giulia. The request is to support the enactment of the regional Law no. 1/2018, General Principles and Implementation Provisions on Accessibility. By taking UD perspective, the aim is to activate a laboratory for innovating public policies, in which the Region and the local administrations work together to revise the contents of planning tools. The starting point consists of providing municipalities with public incentives both to draw Plans for the Removal of Architectural Barriers (PEBAs), and to address their integration into general town plans and public works. In fact, in spite of being established by national laws, up until now the compulsory nature of PEBAs has been nullified by the lack of sanction measures, and the number of the approved ones is still limited. The final output of the agreement signed with the Universities is the realization of a georeferenced (GIS) mapping of accessibility to public buildings, and urban and extra-urban paths in the region.

The first collaboration phase consisted in the delivery of planning guidelines (AA.VV., 2020). Their purpose is to help city administrations use the regional funds for the PEBAs, innovate their contents, and show the strategic role they can play in urban regeneration. The text is not only a practical step-by-step guide. It also proposes a new approach to planning and design, providing both methods and solutions, with regard to: i) setting the construction of PEBAs within a stronger coordination of municipal sectors and offices (town planning, traffic and mobility, public works, etc.); ii) organizing continuous interaction with citizens, in order to consider and provide answers to their needs; iii) taking existing public facilities as the origins and destinations of the accessible itineraries defined by the PEBAs; iv) substituting solutions to single criticalities with more complex spatial upgrading processes, where the interventions on the surfaces of pedestrian paths and pavements, and on their connections, combine with those on urban furniture, lighting, and on the outdoor and indoor accessibility to public buildings. The prompt is to avoid the use of standardized spatial devices and to stimulate 
administrations to take on a more contextual and project-oriented attitude, not only towards the removal of specific obstacles but also towards the overall redesign of public spaces. The work is now proceeding with the construction of a software platform the Region will make available to local municipalities and professionals in order both to facilitate the construction of the PEBAs, and to collect and harmonize information on accessibility on a regional scale. The software will combine the visualization of regional and municipal data on the location and use of existing welfare services with georeferenced mapping tools and integrated electronic sheets. These latter will allow real-time organization of the information gathered during the on-site survey activities PEBAs are based on - from the technical analysis of the places to the matching of critical issues (environmental obstacles and individuals' perceptions).

This experience shows that the improvement of accessibility cannot rely on the implementation of sectoral tools. In fact, the mapping of the physical obstacles to people's movement - although extensive, accurate, and based on participation - tends to reduce the complex theme of accessibility to a punctual and remedial approach. Another important issue refers to the use of ICT devices. The identification and selection of the interventions that are supposed to ensure the effective functioning of collective spaces, equipment, and services is often oriented more by emergencies than by careful planning. A further relevant question therefore concerns how to support municipalities in the construction - as agile and automatic as possible - of knowledge helping decision-making (Chiarelli \& Marchigiani, 2018; Marchigiani, 2020).

\subsection{Recommendations on design and planning solutions}

As a result of Proactive City pilot cases, recommendations to build comprehensive regeneration projects based on accessibility issues can be highlighted. They provide a methodological path and some key steps, addressing further development of the software platform in collaboration with the Region Friuli Venezia Giulia (Figure 3). The first step refers to the selection of the places that plans and projects for accessibility should primarily focus on. As the workshop organized in Grado showed, a preliminary analysis is needed, taking the entire urban context as a reference and deriving information from regional and municipal data sets. The analysis should start from the cartographic mapping of the main public spaces and facilities, their location, and existing/potential physical connections (e.g., schools and cultural equipment, green and open spaces, civic, health, and social care centres, social housing districts, public transport services and hubs, commercial activities). The collection of information about the actual users of this equipment, their places of residence, and movements can further enrich the analytical frame. Moreover, the work of setting action priorities should consider the outcomes from the organization of participatory opening events, and the building of an atlas of the plans and projects the local administration is defining and implementing (e.g., urban plans, mobility plans, public works).

Once the specific intervention area (e.g., a spatial system including walking itineraries, public spaces, built facilities) has been chosen, the second step consists of detailed and contextualized technical and participatory surveys. In this part of the process, the assessment of criticalities and barriers to accessibility should focus not only on quantitative criteria and their actual respondence to normative standards but also on those qualitative and performance aspects (e.g., practicability, safety, environmental quality, usability, and reachability) that the co-assessment process with actual users, tested in the workshop in Trieste, well put into evidence.

Finally, the third step refers to the definition of spatial design solutions and their integration with both overall planning and regeneration strategies, and urban policies dealing with different topics of city governance (from mobility to housing, social and health welfare). Here again, the 
pilot project developed in Grado provided valuable inputs to go beyond sectoral interventions. A proactive city is not just "barrier-free". It is a city where the material reorganization of spaces and facilities is conceived by taking the most vulnerable users' perspective: from the choice of the surface of streets and pavements, to the retrofitting of public buildings, to the conception of new types of equipment (e.g., those freely dedicated to sports and open-air healthy activities).

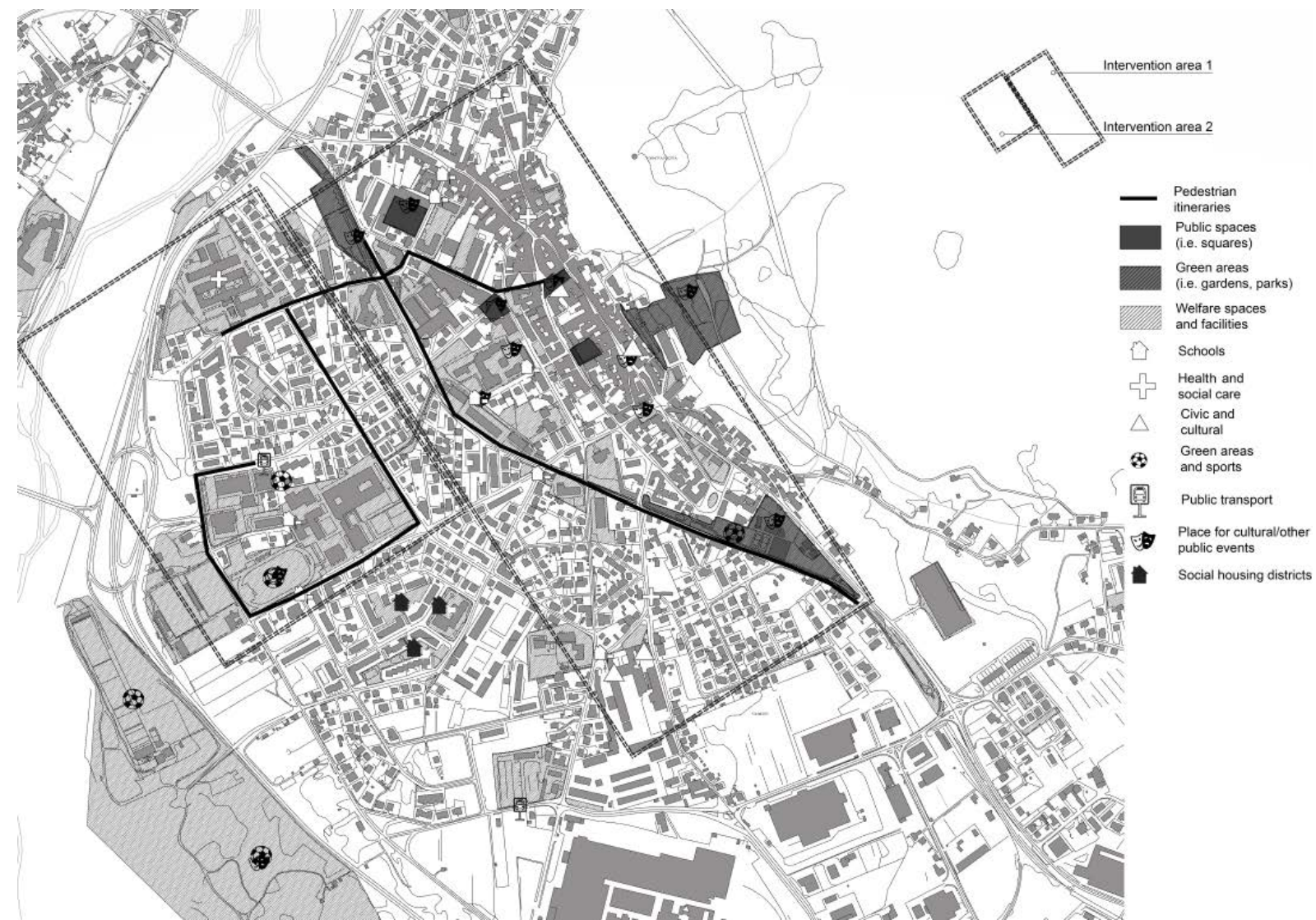

Figure 3: Regional software platform: map of intervention areas, with reference to existing public spaces and facilities, and their potential connections (source: research documentation developed by the Universities of Trieste and Udine, and the Region Friuli Venezia Giulia, 2021).

\section{Discussion: accessibility as a component of ordinary urban regeneration}

The results of the research Proactive City offer inputs to review urban policies, design, and planning tools, confirming the hypothesis that accessibility can be a powerful driver towards comprehensive and people-centred urban regeneration. However, the research outcomes clearly also demonstrate the need of a deeper cultural change in technical approaches. If many solutions to make our cities more accessible are already available, what is often lacking is the attitude to concretely integrate them into the conception of ordinary urban transformations.

\subsection{Public spaces as an enabling infrastructure}

Wearing the lenses of accessibility means assigning a pivotal role both to the direct analysis of the spatial contexts (of their specific constraints against soft and autonomous mobility) and to the acknowledgment of the actual needs of those who daily practice them. The perceived usability of a place goes well beyond the absence of single sensory and architectural barriers. Instead, it refers to a large set of physical and behavioural variables, whose impacts differ according to individuals' capabilities/disabilities, and which profoundly affect the propensity to 
freely move across urban space. Public spaces should be designed for the largest extent of the urban population - starting from those most fragile - with the aim to guarantee inclusive access to collective equipment, while taking into consideration different functioning of individuals. In fact, talking about accessibility for all means providing a high-quality urban environment in which different social practices and bodies can comfortably take place and interact (Bianchetti, 2020). It means assuming a combination of the issues of fruition with those of soft mobility as a prompt to reconceive the material and accessible connection of public spaces and facilities as a welfare service itself. Namely as a service that both plays a strategic prevention and therapeutic role in enabling healthier conditions (for the urban environment and its inhabitants) and helps fight against the exclusion of growing numbers of at-risk urban populations (persons with disabilities, citizens who are transportation disadvantaged for social and economic reasons, as well as the elderly, children, etc.) (DIAUD, 2016). The mere application of quantitative and functional building and planning standards - which currently still regulate accessibility - has frequently led to the conception of separate and disconnected plots and buildings, difficult to access not only for people with disabilities but for everyone. Evidently, to overcome this situation, well-designed routes in between public spaces and facilities are needed.

\subsection{Participation as a continuous co-design process}

In this view, participatory surveys and mapping help understand the often-conflicting effects of enabling/disenabling spaces and negotiate towards more inclusive solutions. In Italy as elsewhere in Europe, the adoption of participatory approaches in urban regeneration (and, specifically, in placemaking processes and projects for inclusive public spaces) is currently recognized as fundamental, and highly recommended by EU initiatives (e.g., URBACT; Bandenhorst, 2019). However, when such approaches are not made compulsory by national and regional laws, they are often ignored. In the Italian national legislation, public debate - which comes closest to the concept of participation in design - is formally required only for largescale infrastructural and architectural works of social relevance. In addition, public debate can be activated for other types and scales of interventions but only if requested by a sufficient number of citizens (Codice dei Contratti Pubblici, Legislative Decree for Public Contracts no. 50, 18 Apr. 2016), in spite of the evident value that understanding of the end users' needs can add to the effectiveness of urban regeneration projects. Indeed, the right to creativity of a designer should be carefully negotiated with the judgment expressed by a variety of stakeholders. Relevant actors and citizens should be invited to co-build and co-validate all the different steps of a design process, and not only during formalized events meant to present and discuss already developed proposals, as is customarily the case when it comes to "ordinary" public urban transformations.

\subsection{Crosscutting the fields of urban policies}

Trying to match and co-ordinately address a variety of conflicting issues (prioritization of traffic flows and parking, safety and comfort of pedestrian and cycling mobility, needs of persons with different disabilities) concretely proves to be a wicked problem (Rittel \& Webber, 1973). That is a problem with many reverberations on spatial justice (Sorkin, 1999) which largely remain underestimated by urban policies. A further important field of innovation thus refers to the systematization and integration of the urban policies and tools that more or less directly deal with accessibility but are often managed by local administrations in a sectoral way (e.g., town plans; traffic, mobility, and parking plans; public works; permissions for commercial occupation). In this sense, the assumption of accessibility (and of PEBAs) as a structural 
component of ordinary and general town plans can help build a reference vision, able to more effectively coordinate the timing and contents of the many public and private interventions that materially affect the use of collective spaces. When talking about healthy and active cities, overcoming the persistent misalignments between planning instruments and housing, social, and health care programs that rule the territorialized organization of welfare services is no less important. This further highlights the importance to foster a radical change in the routines that guide local administrations; the necessity to break the persistence of a "silo thinking" approach (namely the rigid separation of the fields of public action); and the need to strengthen the coordination among urban policies, expertise, and actors involved in urban transformations.

\subsection{Rethinking the role of ICT tools}

ICT tools can help administrations fulfil the aforementioned tasks, but a huge amount of work still needs to be done in this direction. A relevant field of experimentation and innovation regards the construction of technological and GIS integrated platforms, able to harmonize the large amount of data that are already available to the many administrations' sectors and levels; integrate them into a spatial vision; and bring to light the connections between the spatial location of equipment and services, their users and uses. The focus is on data describing the intensity and the type of access to public facilities, local transport, and sites of tourist/cultural interest; facts related to the origin/destination of users; and information on the demographic composition of the residents in different neighbourhoods. These data sets are already automatically and periodically updated, mainly refer to public services addressed to vulnerable groups, and can feed decision support systems, helping not only define where to intervene but also monitor the effects of interventions and, if necessary, re-address them.

However, accessibility is not only a spatial issue, and the interaction of urban planning with ICT tools opens up further operational fields. The adoption of technological applications shows considerable potential for the improvement of the daily use of urban spaces by a large number of persons. Through the provision of up-to-date information on services and their timetables, the physical accessibility of places (e.g., by means of public transport or dedicated parking spaces), and the presence of supports to overcome motor, perceptive, or cognitive barriers, ICT tools allow an easier use of the city as well as a continuous and direct dialogue with the public administrations. This is especially true if technological devices are customizable (adaptable to a person's specific needs) and interactive (capable both of gathering information and suggestions from citizens and city users, and of communicating the status of the interventions carried out to meet their requests). In this sense, the same tools can provide information, and collect citizens' needs and advices in a smarter way.

\section{Conclusions}

The effects of COVID-19 pandemic have dramatically highlighted the strategic role that the usability of fundamental services plays in guaranteeing inclusive and fair urban life conditions. This has helped put accessibility issues at the core of technical and political debate, while stressing the importance of refurbishing urban spaces to make them walkable and enjoyable by the largest extent of the urban population. As sanitary measures have shown, social distancing mainly affects the most fragile persons (the disabled, the elderly, children), preventing or making highly difficult their autonomous access to public spaces and equipment. More careful reflection is thus needed on how to reorganize both welfare facilities (mainly health care and education) and those public spaces that can offer opportunities to reactivate social and health 
practices (mainly parks and streets). If in many Italian cities, as well as all over the world, the management of the post-lockdown phases has seen the realization of pop-up cycle lanes and pedestrian areas as tactical responses to a limited use of public transport (Barbarossa, 2020), a structural and stable adaptation of spaces and material connections according to accessible for all criteria cannot be postponed. Otherwise, there is a significant risk to miss the opportunity to take the pandemic as the driver of significant changes in urban space, welfare, and policies. In other words, our choice stands between two extreme scenarios: on the one hand, the worsening of spatial/social/functional disparities by providing only targeted and temporary solutions, on the other hand, the opening up (similarly to past post-pandemic periods) of a new phase, based on the renewal of skills and tools of urban design, planning, and governance (Pineda \& Corburn, 2020).

From this viewpoint, one of the main challenges is to overcome the still widespread tendency to adopt "particular" technical solutions that, while focusing on physical specialized supports, confine the movement of persons with disabilities to dedicated spaces, produce spatial stigmatization, and prevent social integration. Therefore, there is a strong need to promote actions aimed at raising awareness of the issues of inclusion and enhancement of diversity. The results of the research Proactive City show that taking accessibility as an urban right fosters a radical change in approach, whereas the prompt is to assume detailed spatial devices as ordinary and interconnected components of renovated urban regeneration tools and processes, better addressed to build care-full cities. The reference is to cities that allow their inhabitants to freely move and access public spaces and welfare facilities on a daily basis, according to their different bodies and motilities, material and immaterial needs, cultural and social habits and conditions. If we positively take on the perspective of a deep change, the responsibility of education and research in providing technical and cultural inputs is paramount. The experiences described in the present article move precisely in this direction. Being part of the so-called university public engagement activities (namely the establishment and strengthening of relations with local contexts, stakeholders, and institutions), they pursue multiple purposes. The dissemination and sharing of good practices - as well as the organization of curricular and/or continuous training programs - feed innovation processes. They provide all actors involved with skills and opportunities to think out of the box: the students as future experts can enjoy a different way of learning, based on active and early engagement in the treatment of the complex issues of urban regeneration; the territorial administrations in charge of urban policies can escape routines and emergencies by experimenting with new processes and tools; and the civil society can have voice and offer better knowledge of possible solutions for accessibility through active involvement in co-design processes.

Elena Marchigiani, Department of Engineering and Architecture, University of Trieste, Trieste, Italia (emarchigiani@units.it)

Barbara Chiarelli, Department of Engineering and Architecture, University of Trieste, Trieste, Italia (barbara.chiarelli@phd.units.it)

Ilaria Garofolo, Department of Engineering and Architecture, University of Trieste, Trieste, Italia (ilaria.garofolo@dia.units.it)

\section{Aknowledgments}

The research Proactive city is financed by the University of Trieste (2019-2021), and coordinated by Elena Marchigiani; participants are Sara Basso, Barbara Chiarelli, Ilaria Garofolo, Lucia Parussini, Roberto Prandin, and 
Valentino Pediroda. Proactive city is part of the activities of Trieste Inclusion \& Accessibility Lab (TRIAL) Department of Engineering and Architecture of the University of Trieste, coordinated by Ilaria Garofolo, with Elena Marchigiani and Barbara Chiarelli.

The workshop in Trieste was developed by Barbara Chiarelli, Ghazaleh Afshary, and Silvia Grion. The workshop in Grado was co-organized with the local Municipality (reference person Maria Antonietta Genovese, director of the Technical Sector), coordinated by Elena Marchigiani, and tutored by Sara Basso, Barbara Chiarelli, Ilaria Garofolo, and Valentina Crupi. The scientific coordinators for the agreement on accessibility with the Region Friuli Venezia Giulia are Ilaria Garofolo and Elena Marchigiani (University of Trieste), and Christina Conti (University of Udine). The research group includes Barbara Chiarelli, Elena Frattolin, Mickeal Milocco, Andrea Peraz, and Teresa Sambrotta. The coordinator for the Region Friuli Venezia Giulia is Consuelo Simone (Central Direction Infrastructures and Territory); its strategic partner is the Regional Centre of Information on Architectural and Accessibility Barriers (CRIBA; reference persons are Michele Franz and Paola Pascoli).

Being the result of shared research and intense discussion, the final version of the chapters of this article is to be attributed as following: 1, 2, 3.2, 3.3, 5 to Elena Marchigiani; 3.1 to Barbara Chiarelli; 3.4 to Ilaria Garofolo; 4 to the three authors. A first draft of the article was presented at the City Street 4 Conference organized in 2020 by the University of Ljubljana, the Urban Planning Institute of the Republic of Slovenia, and the Notre Dame UniversityLouaize (Marchigiani et al., 2020).

\section{References}

AA.VV. (2020) PEBA Piano di eliminazione delle barriere architettoniche. Linee guida. Trieste, EUT Edizioni Università di Trieste. Available at:

http://www.regione.fvg.it/rafvg/export/sites/default/RAFVG/infrastrutture-lavoripubblici/FOGLIA1/allegati/14072020_linee_guida_PEBA.pdf (accessed 08 Sept. 2021).

Accolla, A. (2009) Design for all. Il progetto per l'individuo reale. Milano, Franco Angeli.

Adminaité-Fodor, D. \& Jost, G. (2020) How safe is walking and cycling in Europe? Brussels, European Transport Safety Council.

Bandenhorst, W. (2019) How participatory placemaking can help URBACT local groups to develop urban actions for public spaces in our cities. Available at: https://urbact.eu/how-participatory-placemaking-canhelp-urbact-local-groups-develop-urban-actions-public-spaces-our (accessed 08 Sept. 2021).

Barbarossa, L. (2020) The post pandemic city: Challenges and opportunities for a non-motorized urban environment. An overview of Italian cases. Sustainability, 12(17), pp. 1-19. DOI: 10.3390/su12177172

Bencini, M. L., Garofolo, I. \& Arenghi, A. (2018) Implementing universal design and the ICF in higher education: Towards a model that achieves quality higher education for all. In: Craddock, G. et al. (eds.), Transforming our world through design, diversity and education, pp. 464-472. Amsterdam, Berlin, Washington, IOS Press.

Bianchetti, C. (2020) Bodies: Between space and design. Berlin, Jovis. DOI: 10.1515/9783868599497

Blečić, I., Congiu, T., Fancello, G. \& Trunfio, G. A. (2020) Planning and design support tools for walkability: A guide for urban analysts. Sustainability, 12(11), pp. 1-18. DOI: 10.3390/su12114405

Brain, D. (2019) Reconstituting the urban commons: Public space, social capital and the project of urbanism. Urban Planning, 4(2), pp. 169-182. DOI: 10.17645/up.v4i2.2018

Chiarelli, B. \& Marchigiani, E. (2018) Con le "lenti" della fruibilità: strumenti interattivi e tecnologici per rigenerare gli spazi urbani. Urbanistica Informazioni, 280-281, pp. 96-98.

Cities for All (2019) Inclusive and accessible cities. Available at: https://www.durban2019.uclg.org/sites/default/files/201910/Inclusive\%20\%26\%20Accessible\%20Cities_PolicyPaper.pdf (accessed 08 Sept. 2021).

Comune di Trieste (2019) Piattaforma partecipativa. Piazza Sant'Antonio. Available at: https://piattaformapartecipativa.online.trieste.it/santantonio (accessed 08 Sept. 2021).

Commission on Social Determinants of Health (2008) Closing the gap in a generation: Health equity through action on the social determinants of health. Available at:

https://www.who.int/social_determinants/thecommission/finalreport/en (accessed 08 Sept. 2021).

DIAUD - Disability Inclusive and Accessible Urban Development Network (2016) The inclusion imperative: Towards disability-inclusive and accessible urban development - key recommendations for an inclusive urban agenda. Available at: https://www.susana.org/en/knowledge-hub/resources-andpublications/library/details/3080 (accessed 08 Sept. 2021).

Dorato, E. (2020) Preventive urbanism. The role of health in designing active cities. Macerata, Quodlibet. DOI: $10.2307 /$ j.ctv13xpqzg

European Commission (2010) European disability strategy. Available at: https://eur-lex.europa.eu/legalcontent/EN/TXT/?uri=LEGISSUM\%3Aem0047 (accessed 08 Sept. 2021). 
European Commission (2020) Commission staff working document guidance to Member States Recovery and Resilience Plans. Available at:

https://ec.europa.eu/info/sites/info/files/3_en_document_travail_service_part1_v3_en_0.pdf (accessed 08 Sept. 2021).

European Commission (2021) New European Bauhaus: Shaping more beautiful, sustainable and inclusive forms of living together. Available at: https://europa.eu/new-european-bauhaus/index_en (accessed 08 Sept. 2021).

Garofolo, I., Chiarelli, B. \& Grion, S. (2018) Percorsi inclusivi e partecipati per la fruibilità degli spazi urbani: il caso studio LabAc. In: Angelucci, F. (ed.) Smartness e healthness per la transizione verso la resilienza. Orizzonti di ricerca interdisciplinare sulla città e il territorio, pp. 307-324. Milano, Franco Angeli.

Francis, M. (1987) The making of democratic streets. In: Vernez Moudon, A. (ed.) Public streets for public use, pp. 23-39. New York, Van Nostrand Reinhold Company.

Kaufmann, V. (2011) Re-thinking the city: Urban dynamics and motility. Lausanne, EPFL Press.

Marchigiani, E. (2020) An accessible city is a healthy and people-centred smart city. International Journal of Planning and Smart Cities, 1(2), pp. 59-79. DOI: 10.4018/IJUPSC.2020070105

Marchigiani, E. (2022) Healthy and caring cities: Accessibility for all and the role of urban spaces in reactivating capabilities. In: Gabauer A., Knierbein S., Cohen N., Lebuhn H., Trogal K., Viderman T. \& Haas, T. (eds.) Care and the city: Encounters with Urban Studies. New York, London: Routledge, pp. 75-87.

Marchigiani, E., Garofolo, I. \& Chiarelli, B. (2020) Rethinking public spaces: Accessibility for all as a driver to integrate mobility, health and ecological issues. In: Fikfak, A., Nikšić, M., Mady, C., Bizjak, I. \& Blenkuš, M. (eds.) Streets for 2030: Proposing streets for integrated, and universal Mobility. Book of proceedings, pp. 15-24. Ljubljana, University of Ljubljana, Faculty of Architecture, Urban Planning Institute of the Republic of Slovenia.

Nike (2015) Designed to move: Active cities. Available at: https://participatoryplanning.ca/tools/designed-moveactive-cities-guide-city-leaders (accessed 08 Sept. 2021).

Pineda, V.S. \& Corburn, J. (2020) Disability, urban health equity, and the coronavirus pandemic: Promoting cities for all. Journal of Urban Health, 97(3), pp. 336-341. DOI: 10.1007/s11524-020-00437-7

Rittel, H. W. \& Webber, M. M. (1973) Dilemmas in a general theory of planning. Policy Science, 4(2), pp. 155169. DOI: $10.1007 / \mathrm{BF} 01405730$

Rupprecht Consult (ed.) (2019) Guidelines for developing and implementing a sustainable urban mobility plan: Second edition. Available at:

https://www.eltis.org/sites/default/files/sump_guidelines_2019_interactive_document_1.pdf (accessed 08 Sept. 2021).

Sen, A. (1987) Commodities and capabilities. Oxford, Oxford University Press.

Shah, P., Hamilton, E., Armendaris, F. \& Lee, H. (2015) World: Inclusive cities approach paper. Washington, The World Bank.

Schön, D. (1984) The reflective practitioner: How professionals think in action. New York, Basic Books.

Speck, J. (2018) Walkable city rules: 101 steps to making better places. Washington, Island Press. DOI: 10.5822/978-1-61091-899-2

Sorkin, M. (1999). Introduction: Traffic in democracy. In: Copjec, J. \& Sorkin, M. (eds.) Giving ground: The politics of propinquity, pp. 1-18. London, New York, Verso Books.

Tsouros, A.D. (2015) Twenty-seven years of the WHO European Healthy Cities Movement: A sustainable movement for change and innovation at the local level. Health Promotion International, 30(1), pp. 13-17. DOI: $10.1093 /$ heapro/dav046

United Nations (2006) Convention on the rights of persons with disabilities (UN-CRPD). Available at: https://www.un.org/development/desa/disabilities/convention-on-the-rights-of-persons-withdisabilities.html (accessed 08 Sept. 2021).

United Nations (2016), Good practices of accessible urban development. Available at: https://www.un.org/disabilities/documents/desa/good_practices_in_accessible_urban_development_octob er2016.pdf (accessed 08 Sept. 2021).

World Health Organization (2001) International classification of functioning, disability and health (ICF-DH). Available at: https:/www.who.int/classifications/icf/en (accessed 08 Sept. 2021). 